\title{
Los usos del pasado durante la Edad Media
}

\author{
Begoña Torre Miguel \\ Universidad DE OviEdo \\ betomi89@hotmail.com
}

The uses of the past in the Middle Ages 

La pervivencia de la Antigüedad durante la Edad Media fue posible debido al constante giro de la mirada de esta última hacia la primera. Pero los ojos medievales no siempre se limitaron a la pasiva observación del pasado, sino que este examen conllevó el (re)empleo, la interpretación y la adaptación de ese pasado a su propia realidad. En efecto, el interés por lo "clásico» ha sido, como afirma $S$. Settis, el mecanismo más poderoso de renovación durante todas las épocas. Sin embargo, a mediados del siglo xix Jean-Jacques Ampère advirtió por primera vez de la existencia en la cultura occidental de dos renacimientos anteriores al Renacimiento con mayúsculas: el primero en época de Carlomagno, y el segundo en el siglo xir. Esto no sólo daba un giro en la perspectiva "oscura» y "anticlásica» de la Edad Media, sino que provocó un profundo debate al respecto, sobre todo en lo referente al uso del término «renacimiento». En la actualidad, más allá de la controversia conceptual, es comúnmente aceptado que la época medieval no sólo vivió frente a frente con la Antigüedad, sino que, en determinados momentos, y concretamente en los señalados por Ampère, lo clásico gozó de un impulso y una efervescencia particulares que hicieron de la Antigüedad un modelo a seguir en todos los ámbitos de la cultura (E. Panofsky).

En torno a esta idea, tuvo lugar en la Facultad de Filosofía y Letras, los días I4, I5 y I6 de octubre de 2019, el
VII Congreso Internacional de Jóvenes Medievalistas ${ }^{1}$. La voluntad de este séptimo encuentro fue mantener la labor iniciada por los foros de jóvenes medievalistas que se celebraron en Cáceres hasta el año 20I6, y cuya continuidad fue posible gracias a la iniciativa de la Universidad Autónoma de Madrid como sede del encuentro en febrero de 20I8. Así, en el encuentro de 2019 contamos con seis ponencias marco llevadas a cabo por especialistas nacionales e internacionales que permitieron mostrar a los participantes la plural y efectiva utilización del pasado antiguo durante el medievo: Raquel Alonso Álvarez (Profesora Titular de la Universidad de Oviedo), Sergio Vidal Álvarez (Jefe del Departamento de Antigüedades Medievales del Museo Arqueológico Nacional), Daniel Rico Camps (Profesor Titular de la Universidad Autónoma de Barcelona), Patrizio Pensabene (Catedrático emérito de la Universidad de La Sapienza, Roma), Lorenzo Arias Páramo (Profesor Titular de la Universidad de Oviedo) y Mar Díaz González (Profesora Titular de la Universidad de Oviedo). A todos ellos me gustaría mostrar mi más profundo agradecimiento por la participación y el apoyo a estos coloquios dirigidos, fundamentalmente, a quienes estamos empezando.

Del mismo modo, de las diversas comunicaciones expuestas en este encuentro, a cuyos autores quiero

${ }^{1}$ La organización de este encuentro se benefició de una de las «Ayudas a Organización de Congresos» del Plan Propio de la Universidad de Oviedo 20I9 (PAPI-I9-CONG-I3), así como del patrocinio de la Sociedad Española de Estudios Medievales (SEEM). 
también agradecer su participación, sólo verán la luz aquí tres de ellas tras su evaluación por pares. En primer lugar, Pablo Cucart Espina (Universidad de Granada) mostrará en su artículo cómo tras la conquista de Baeza en 1226 por las tropas de Fernando III, se inició un proceso de restauración de la diócesis que hizo necesario el recurso a documentos antiguos para establecer «su nueva» delimitación. Sin duda, este ejemplo propuesto por Cucart pone sobre la mesa uno de los motivos principales por los que en el medievo los dos grandes poderes que constituyen la «sociedad bicéfala» (J. Le Goff) recurrieron al pasado: la legitimación. En segundo lugar, la aportación de Antonio Pio Di Cosmo (ISACCL, Bucarest. Universidad Católica de Cuyo) nos trasladará a la monarquía siciliana, cuyo recurso a la fórmula antigua "a Deo coronatus» y al pórfido como material preferido, evidencian, nue- vamente una clara estrategia de legitimación. En este caso, la legitimación conllevó también el recurso físico a la Antigüedad, en este caso a través de la reutilización de elementos de pórfido, uno de los materiales más codiciados durante el medievo. Finalmente, con Alberto González García (Universidade de Vigo) regresaremos a un territorio cercano, Flavionavia Paesicorum, a través de un trabajo numismático basado en los dos únicos tremisses conservados. De nuevo, este artículo de González García da buena cuenta de cómo hay que hablar más de continuidad que de ruptura y de cómo la identificación de Flavionavia con Pravia, elegida sede regia en época de la monarquía asturiana por Adosinda y Silo (774- †783), tuvo mucho que ver con su importancia pasada, sin mencionar el neovisigotismo que caracterizó a la monarquía asturiana a partir, al menos, de Alfonso III (†9Io). 